\title{
Fish consumption, mercury exposure, and the risk of cholesterol profiles: findings from the Korea National Health and Nutrition Examination
} Survey 2010-2011

\author{
Yong Min Cho \\ Institute for Life and Environment Technology, Smartive Corporation, Seoul, Korea
}

\begin{abstract}
In this study, the associations between mercury $(\mathrm{Hg})$ exposure and cholesterol profiles were analyzed, and increased $\mathrm{Hg}$ levels and cholesterol profiles according to the amount of fish consumption were evaluated. Data on levels of blood $\mathrm{Hg}$, the frequency of fish consumption, total blood cholesterol (TC), high-density lipoprotein cholesterol (HDL-C), low-density lipoprotein cholesterol (LDL-C), and triglyceride (TG) in 3951 adults were obtained from the Korea National Health and Nutrition Examination Survey 2010-2011 database. To compare the distribution for each log-transformed indicator, Student's $t$-test and analysis of variance were carried out, and the groups were classified according to the frequency of fish consumption through linear regression analysis; the association between $\mathrm{Hg}$ level and cholesterol profiles in each group was analyzed. The blood $\mathrm{Hg}$ levels (arithmetic mean, median, and geometric mean) for all target participants were $4.59,3.66$, and $3.74 \mu \mathrm{g} / \mathrm{L}$, respectively. The high cholesterol group, low HDL-C group, and high TC group showed a statistically and significantly higher blood $\mathrm{Hg}$ level than the low-risk group. In both sexes, as the frequency of fish consumption increased, blood Hg level also increased, but TC, HDL-C, LDL-C, and TC did not show a similar trend. Increased blood $\mathrm{Hg}$ level showed a significant association with increased TC and LDL-C. This statistical significance was maintained in the group with less frequent fish consumption ( $<4$ times per month), but the group with frequent fish consumption ( $>8$ times per month) did not show a similar trend. The results of this study suggest that fish consumption increases the level of $\mathrm{Hg}$ exposure, and that as the level of $\mathrm{Hg}$ exposure increases, the levels of cholesterol profiles increase. However, this study also suggests that the levels of cholesterol profiles in those with frequent fish consumption can be diminished.
\end{abstract}

Keywords Mercury, Methylmercury, Fish consumption, Cholesterol profiles, Korea National Health and Nutrition Examination Survey

\author{
Correspondence: Yong Min Cho \\ Institute for Life and Environment \\ Technology, Smartive Corporation, 58 \\ Dobong-ro 11ona-gil, Dobong-gu, Seoul \\ 01454, Korea \\ E-mail: neworder@smartive.biz \\ Received: October 25, 2016 \\ Accepted: August 29, 2017 \\ Published: August 31, 2017 \\ This article is available from: http://e-eht.org/
}

\section{INTRODUCTION}

In the general population, the major pathways of exposure to mercury $(\mathrm{Hg})$ include contact with environmental contaminants, use of Hg-containing products, dental amalgam, and con- sumption of contaminated food including fish. Among these, fish consumption is associated with methylmercury $(\mathrm{MeHg})$ exposure [1]. Whole blood total $\mathrm{Hg}$ level is used in the evaluation of $\mathrm{MeHg}$ exposure levels [2,3]. In many biomonitoring studies, a significant association between fish consumption and 
an increase in blood $\mathrm{Hg}$ level in adults and children was reported [4-9]. Moreover, it is known that the blood Hg levels of Asians, who consume a large amount of fish, are higher than those of people in Western countries $[6,10]$.

Chronic MeHg exposure is associated with cardiovascular disease (CVD) and cholesterol profiles [11]. It has been reported that $\mathrm{Hg}$ increases the risk of hypertension, carotid atherosclerosis, and myocardial infarction [12-15]. It has also been reported that the $\mathrm{Hg}$ level in the body is significantly associated with increases in serum ferritin, systolic blood pressure, diastolic blood pressure, total cholesterol, triglyceride, and waist to hip ratio [16-18].

However, the consumption of omega- 3 fatty acids due to fish consumption also has a beneficial effect in preventing CVD and coronary heart disease $[19,20]$. In other words, fish consumption undesirably increases $\mathrm{MeHg}$ and desirably increases omega-3 fatty acids at the same time in terms of CVD. Therefore, organizations such as the World Health Organization and US Food and Drug Administration have identified those who are more susceptible to the effects of $\mathrm{Hg}$, and recommend consumption of an appropriate amount of fish containing higher levels of $\mathrm{Hg}$ rather than complete avoidance.

This study analyzed the association between $\mathrm{Hg}$ exposure level and cholesterols profiles as an indicator of CVD risks for dyslipidemia using biomonitoring data for the general population obtained by a national survey. The purpose of this analysis was to verify and generalize previous results regarding the association between $\mathrm{Hg}$ exposure and dyslipidemia risks increase in $\mathrm{Hg}$ level according to fish consumption and the associated the level of cholesterol profiles were evaluated.

\section{METHODS}

\section{Population in the Korea National Health and Nutrition Examination Survey}

The Korea National Health and Nutrition Examination Survey (KNNHANES) is a nationwide survey carried out by the Korea Centers for Disease Control and Prevention (KCDC). A sample representative of the entire population of Korea was determined from the results of a census; the 1st stratification was based on districts, and the 2nd stratification was based on sex and age. The KNHANES was first conducted in 1998, and the participants in the present study were the survey participants for 2010-2011; the survey questions regarding fish consumption were standardized in the KNHANES V (2010-2012). Detailed information regarding the KNHANES can be obtained from other studies $[7,21]$.

The number of target participants in the KNHANES V (2010-
2012) was 25 533, and the number in 2010-2011 was 17476. Among these 17476 in 2010-2011 participants, the number of adults over 19 years old was 13165 . The annual target for blood heavy metal testing in KNHANES V was approximately 2400 people over 10 years old, and the final number of target adults with valid data for both blood tests and food consumption frequency in 2010-2011 was 3951.

The KNHANES was carried out with the approval of the KCDC Committee of Ethics. The institutional review board approval numbers for the 1st (2010) and 2nd year (2011) of KNHANES V are 2010-02CON-21-C and 2011-02CON-06-C, respectively.

\section{Data Collection}

The KNHANES consists of health, nutrition, and health screening surveys. The key variables used for the analysis in this study include blood $\mathrm{Hg}$ level, frequency of fish consumption, and primary indicators for dyslipidemia, including TC, highdensity lipoprotein cholesterol (HDL-C), low-density lipoprotein cholesterol (LDL-C), and TG. In addition, other factors reported to affect the primary variables were included in the analysis. For example, smoking and alcohol consumption are associated with an increase in blood $\mathrm{Hg}$ level [22] as well as dyslipidemia. And obesity also [23].

The general characteristics of the target participants and the information regarding their smoking history, alcohol consumption, and family history of CVD were collected through an interview. After the interview, the height and weight were measured, and the body mass index (BMI) was calculated. The blood test items included TC, HDL-C, LDL-C, TG, and Hg concentration. Sampling was carried out in the morning, after a minimum 8-hour fast.

The 2010-2011 KNHANES used a simplified food consumption survey table consisting of 63 food items including fish. This survey asks the frequency of consumption for each food type per day, week, and month. The survey listed 9 types of fish consumed most frequently by Koreans, including mackerel, tuna, yellow fish, pollock, anchovy, fish cake, squid, clams, and pickled seafood; tuna and mackerel are known to have a high $\mathrm{Hg}$ content and were included in the analysis [24].

\section{Analysis of Blood Samples}

Blood TC, HDL-C, LDL-C, and TG were analyzed using enzymatic methods. A Hitachi Automatic Analyzer 7600 (Hitachi, Tokyo, Japan) was used for the analysis; the reagents used were Pureauto SCHO-N (Sekisui, Tokyo, Japan) for TC, Cholesteset N HDL (Sekisui) for HDL-C, Cholesteset LDL (Sekisui) for LDL-C, and Pureauto S TG-N (Sekisui) for TG. To evaluate 
the $\mathrm{Hg}$ level in whole blood, a 3-mL sample was collected in a commercial heparinized tube. The sample was kept in a freezer until transfer to the analysis laboratory (Neodin Medical Institute, Seoul, Korea). Hg was analyzed using the gold-amalgam method with DMA-80 (Milestone, Sorisole, Italy).

\section{Variable Definitions}

In order to evaluate the risk of dyslipidemia according to the level of $\mathrm{Hg}$ exposure, high-risk groups were classified into a high cholesterol group (hypercholesterolemia), a low HDL-C group (low HDL-cholesterolemia), and a high TG group (hypertriglyceridemia). The high cholesterol group included target participants whose TC level was more than $240 \mathrm{mg} / \mathrm{dL}$ after an 8-hour fast, or who were taking a cholesterol-reducing drug. The low HDL-C group included target participants whose level was below $40 \mathrm{mg} / \mathrm{dL}$, and the high TG group include those whose level was $200 \mathrm{mg} / \mathrm{dL}$ or higher [25]. Since the high LDL-C group was not defined in the KNHANES, only the high TC group, low HDL-C group, and high TG group were assessed in this study [26].

The frequency of consumption of all types of tuna and mackerel (raw, canned, grilled, steamed, etc.) was asked, and the result was converted into the number of times consumed per month.

As confounders, BMI, smoking status, alcohol consumption and family history of CVD were considered. Family history of CVD includes parental dyslipidemia, hypertension, and hyperlipidemia.

\section{Statistical Analysis}

The Kolmogorov-Smirnov test showed that the continuous variables including blood $\mathrm{Hg}$ level, TC, HDL-C, LDL-C, and TG analyzed in this study had a right-skewed shape without normality. Therefore, the arithmetic mean, median, geometric mean (GM), and geometric standard deviation (GSD) were calculated in this study to report representative values. The log-transformed value was applied as a variable in statistical analysis. Student's $t$ test was used to compare the distribution of blood $\mathrm{Hg}$ level in hypertensive and dyslipidemic high-risk groups with levels in low-risk groups, and analysis of variance was carried out to compare the distribution of each continuous variable according to the frequency of fish consumption, and to determine any increasing or decreasing tendency. The groups were classified according to the frequency of fish consumption, and linear regression analysis was carried out to analyze the correlation between the level of blood $\mathrm{Hg}$ exposure and dyslipidemia indicators in each group. This linear regression model included variables such as age, BMI, drinking, smoking, and family history of CVD.
Statistical significance was verified with a $95 \%$ confidence interval, and SPSS version 23 (IBM Corp., Armonk, NY, USA) was used for the analysis. The data of KNHANES apply stratified, clustered, and systematic sampling methods, not simple random sampling. In addition, to assure representation of Korean whole population, the weighting is given for the population structure of data. Therefore, the method for analyzing complex sample was applied of SPSS (IBM Corp.) [27].

\section{RESULTS}

Table 1 shows the general characteristics of the 3951 target participants in this study. The average age was 45.20 years and the sex ratio of men to women was 1.03 . The median of concentrations of blood $\mathrm{Hg}$ was $3.7 \mu \mathrm{g} / \mathrm{L}$. The proportions of target participants who consumed fish less than 4 times a month was $46.0 \%$, followed by $25.1 \%$ for $4-8$ times per month and $13.5 \%$ for more than 8 times a month. The proportion of target participants diagnosed with high cholesterol, low HDL-C, and high TG were $13.5 \%, 23.8 \%$, and $12.3 \%$, respectively.

The GM and GSD of the blood Hg level of 535 target participants included in the high cholesterol group (high-risk group) was 3.94, $1.88 \mu \mathrm{g} / \mathrm{L}$, which was statistically and significantly higher than that $(3.69,1.84 \mu \mathrm{g} / \mathrm{L})$ of the low-risk group $(\mathrm{n}=3278)(p$ value $=0.025$ ). The blood $\mathrm{Hg}$ levels of the low HDL-C group $(\mathrm{n}=941)$ were $3.95,1.91 \mu \mathrm{g} / \mathrm{L}$, respectively, and were significantly higher than those $(3.67,1.83 \mu \mathrm{g} / \mathrm{L})$ of the low-risk group $(\mathrm{n}=2924)(p$-value $=0.002)$. The blood Hg levels of the highTG group $(\mathrm{n}=487)$ were $4.37,1.93 \mu \mathrm{g} / \mathrm{L}$, respectively, and were significantly higher than those $(3.60,1.83 \mu \mathrm{g} / \mathrm{L})$ of the low-risk group $(\mathrm{n}=2615)(\mathrm{p}$-value $<0.001)($ Table 2$)$.

Fish consumption was grouped by frequency of less than 4 times a month, 4-8 times a month, and more than 8 times a month, and the blood $\mathrm{Hg}$ levels and dyslipidemia indicators were compared between groups (Figure 1). In females, the blood Hg levels (GM, GSD) of the group with consumption less than 4 times a month were 3.05 , and $1.75 \mu \mathrm{g} / \mathrm{L}$, respectively; the levels of the group with consumption 4-8 times a month were 3.10 , and $1.62 \mu \mathrm{g} / \mathrm{L}$, respectively; and the levels of the group with consumption more than 8 times a month were 3.32, and $1.75 \mu \mathrm{g} / \mathrm{L}$, respectively. As the frequency of fish consumption increased in females, the blood $\mathrm{Hg}$ level also in creased, and this trend was statistically significant $(p$-trend $=0.022)$. This trend was also statistically significant in males $(p$-trend $<0.001)$.

The median of TC levels in the group with consumption less than 4 times a month were $188.00 \mathrm{mg} / \mathrm{dL}$ for females, and $185.00 \mathrm{mg} / \mathrm{dL}$ for males. The median of blood $\mathrm{Hg}$ in the group with consumption 4-8 times a month were $179.00 \mathrm{mg} / \mathrm{dL}$ for 
Table 1. General characteristics of the study population in KNHANES 2010-2011

\begin{tabular}{|c|c|c|c|c|}
\hline Characteristics & & Female $(n=2001)$ & Male $(n=1950)$ & All $(n=3951)$ \\
\hline Age (year) & $\begin{array}{l}\text { Mean } \pm S D \\
20-29 \\
30-39 \\
40-49 \\
50-59 \\
60-69 \\
\geq 70\end{array}$ & $\begin{array}{l}45.02 \pm 14.58 \\
392(19.6) \\
404(20.2) \\
404(20.2) \\
404(20.2) \\
347(17.3) \\
50(2.5)\end{array}$ & $\begin{array}{c}45.39 \pm 14.46 \\
353(18.1) \\
398(20.4) \\
403(20.7) \\
399(20.5) \\
331(17.0) \\
66(3.4)\end{array}$ & $\begin{array}{l}45.20 \pm 14.52 \\
745(18.9) \\
802(20.3) \\
807(20.4) \\
803(20.3) \\
678(17.2) \\
116(2.9)\end{array}$ \\
\hline Blood Hg ( $\mu \mathrm{g} / \mathrm{L})$ & Median & 3.0 & 4.5 & 3.7 \\
\hline T-cholesterol (mg/dL) & Median & 184.0 & 186.5 & 185.0 \\
\hline HDL-cholesterol (mg/dL) & Median & 50.0 & 44.0 & 47.0 \\
\hline LDL-cholesterol (mg/dL) & Median & 110.0 & 112.0 & 111.0 \\
\hline Triglyceride (mg/dL) & Median & 91.0 & 127.0 & 107.0 \\
\hline Frequency of fish intake $(/ \mathrm{mo})^{\mathrm{a}}$ & $\begin{array}{l}<4 \\
4-8 \\
>8\end{array}$ & $\begin{array}{r}1000(50.0) \\
536(26.8) \\
274(13.7)\end{array}$ & $\begin{array}{l}818(41.9) \\
455(23.3) \\
258(13.2)\end{array}$ & $\begin{array}{r}1818(46.0) \\
991(25.1) \\
532(13.5)\end{array}$ \\
\hline Prevalence & $\begin{array}{l}\text { High cholesterol } \\
\text { Low-HDL cholesterol } \\
\text { High-triglyceride }\end{array}$ & $\begin{array}{l}304(15.2) \\
303(15.1) \\
153(7.6)\end{array}$ & $\begin{array}{l}231(11.8) \\
638(32.7) \\
334(17.1)\end{array}$ & $\begin{array}{l}535(13.5) \\
941(23.8) \\
487(12.3)\end{array}$ \\
\hline Family history of CVD & & $821(41.0)$ & $735(37.7)$ & $1,556(39.4)$ \\
\hline Current smoking & & $112(5.6)$ & $878(45.0)$ & $990(25.0)$ \\
\hline Drinking (every week) & & $184(9.1)$ & $717(36.7)$ & $901(22.8)$ \\
\hline $\mathrm{BMI}$ & Mean $\pm S D$ & $23.22 \pm 3.53$ & $24.14 \pm 3.10$ & $23.67 \pm 3.36$ \\
\hline
\end{tabular}

Values are presented as number (\%).

KNHANES, Korea National Health and Nutrition Examination Survey; SD, standard deviation; Hg, mercury; T, total; HDL, high-density lipoprotein; LDL, low-density lipoprotein; CVD, cardiovascular diseases; BMl, body mass index.

aBlue-colored fish (including tuna, mackerel).

Table 2. Comparisons of blood mercury levels in the high-risk group and low-risk group according to cholesterol profiles

\begin{tabular}{|c|c|c|c|c|c|c|}
\hline Variable & & $\mathrm{n}$ & GM & GSD & Median & $p$-value ${ }^{\mathrm{a}}$ \\
\hline High cholesterol & $\begin{array}{l}\text { Yes } \\
\text { No }\end{array}$ & $\begin{array}{r}535 \\
3278\end{array}$ & $\begin{array}{l}3.94 \\
3.69\end{array}$ & $\begin{array}{l}1.88 \\
1.84\end{array}$ & $\begin{array}{l}3.76 \\
3.60\end{array}$ & 0.02 \\
\hline Low-HDL cholesterol & $\begin{array}{l}\text { Yes } \\
\text { No }\end{array}$ & $\begin{array}{r}941 \\
2924\end{array}$ & $\begin{array}{l}3.95 \\
3.67\end{array}$ & $\begin{array}{l}1.91 \\
1.83\end{array}$ & $\begin{array}{l}4.04 \\
3.53\end{array}$ & 0.002 \\
\hline High triglyceride & $\begin{array}{l}\text { Yes } \\
\text { No }\end{array}$ & $\begin{array}{r}487 \\
2615\end{array}$ & $\begin{array}{l}4.37 \\
3.60\end{array}$ & $\begin{array}{l}1.93 \\
1.83\end{array}$ & $\begin{array}{l}4.35 \\
3.50\end{array}$ & $<0.001$ \\
\hline
\end{tabular}

Unit: ug/L.

HDL, high-density lipoprotein; GM, geometric mean; GSD, geometric standard deviation.

aStudent's $t$-test (calculated by using log-transformed blood mercury levels).

females, and $185.00 \mathrm{mg} / \mathrm{dL}$ for males; and the median in the group with consumption more than 8 times a month were $183.50 \mathrm{mg} / \mathrm{dL}$ for females, and $187.00 \mathrm{mg} / \mathrm{dL}$ for males, with no trend of significant increase or decrease ( $p$-trend $=0.105$ for females; 0.970 for males). The median of HDL-C levels in the female group with consumption less than 4 times a month was $50.00 \mathrm{mg} / \mathrm{dL}$; the median in the female group with consumption 4-8 times a month was $50.00 \mathrm{mg} / \mathrm{dL}$; and the median in the female group with consumption more than 8 times a month was $53.00 \mathrm{mg} / \mathrm{dL}$, showing a trend of increase, but the male groups showed no trend of significant increase. The median of corresponding HDL-C levels in the male group with consumption less than 4 times a month was $44.00 \mathrm{mg} / \mathrm{dL}$; the median in the male group with consumption 4-8 times a month was 45.00 $\mathrm{mg} / \mathrm{dL}$; and the median in the male group with consumption more than 8 times a month was $44.50 \mathrm{mg} / \mathrm{dL}$ ( $p$-trend $<0.001$ for females; 0.488 for males). The median of LDL-C levels in the female group with consumption less than 4 times a month was $114.00 \mathrm{mg} / \mathrm{dL}$; the median in the female group with consumption 4-8 times a month was $107.00 \mathrm{mg} / \mathrm{dL}$; and the median in the female group with consumption more than 8 times a month was $107.00 \mathrm{mg} / \mathrm{dL}$ ( $p$-trend $=0.018$ ); the median in the male group with consumption less than 4 times a month was $111.00 \mathrm{mg} / \mathrm{dL}$; the median in the male group with consumption 4-8 times a month was $112.00 \mathrm{mg} / \mathrm{dL}$; and the median in the male group with consumption more than 8 times a month was $114.00 \mathrm{mg} / \mathrm{dL}$ ( $p$-trend $=0.439$ ). The median of TG levels in the female group with consumption less than 4 times a 

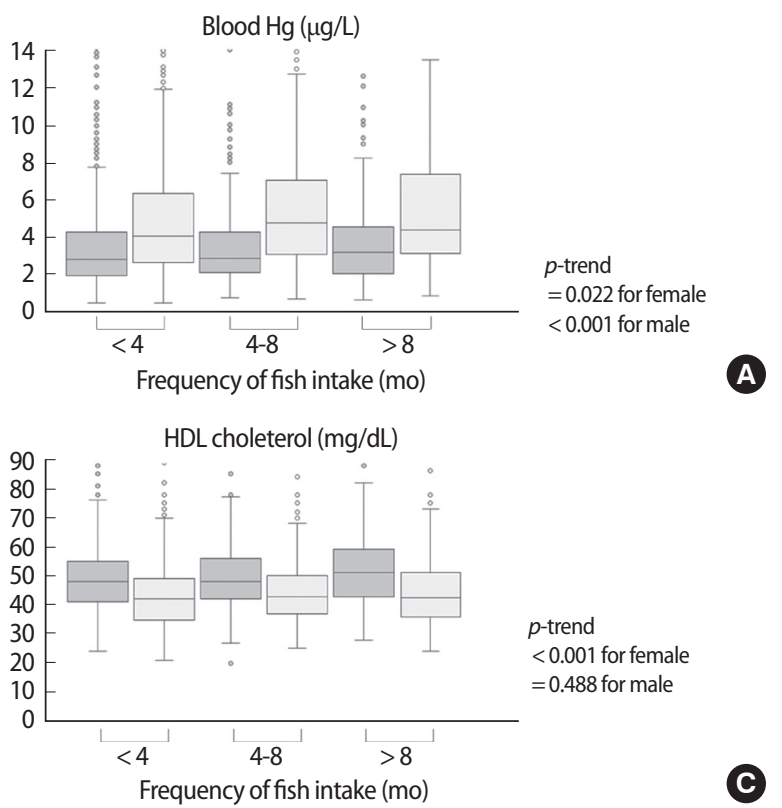

$p$-trend

$<0.001$ for female

$=0.488$ for male

Triglyceride $(\mathrm{mg} / \mathrm{dL})$

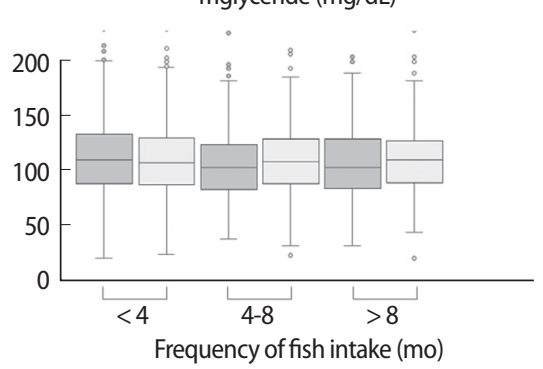

C

p-trend

$<0.001$ for female

$=0.099$ for male

E

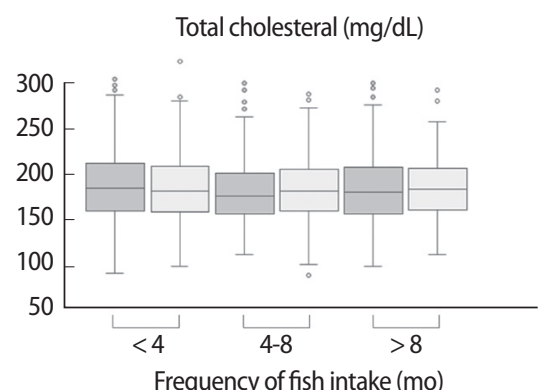

$p$-trend

$=0.105$ for female

$=0.970$ for male
LDL choleterol (mg/dL)

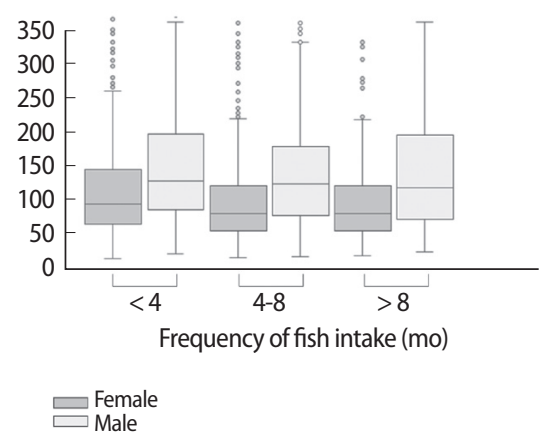

p-trend

$=0.018$ for female $=0.439$ for male

B

D

Figure 1. Frequency of blue-colored fish intake per month and the levels of blood mercury (A) and cholesterol profiles (B: total choleterol, C: HDL choleterol, D: LDL choleterol, and E: triglyceride). The $p$-trend calculated by analysis of variance (calculated by using log-transformed blood $\mathrm{Hg}$ levels). The $\mathrm{x}$ axis shows the frequency of fish intake per month; blue-colored fish include tuna and mackerel. Hg, mercury; HDL, high-density lipoprotein; LDL, lowdensity lipoprotein.

Table 3. Coefficients (beta) for linear regression analysis of each log-transformed value of cholesterol profiles as the dependent variables, and log-transformed levels of blood mercury as the independent variable ${ }^{\mathrm{a}}$

\begin{tabular}{|c|c|c|c|c|c|c|}
\hline \multirow{2}{*}{ Dependent variable } & \multicolumn{6}{|c|}{ Values according to the frequency of fish intake per month, and for gender and total } \\
\hline & $<4(\mathrm{n}=1818)$ & $4-8(n=991)$ & $>8(n=532)$ & Female $(n=2001)$ & Males $(n=1950)$ & Total $(n=3951)$ \\
\hline T-cholesterol & $0.091^{\star *}$ & $0.095^{\star *}$ & 0.080 & $0.072^{* \star}$ & $0.109^{* *}$ & $0.089^{* *}$ \\
\hline HDL-cholesterol & 0.032 & 0.031 & 0.002 & $0.074^{\star \star}$ & 0.015 & 0.014 \\
\hline LDL-cholesterol & $0.074^{\star \star}$ & 0.062 & 0.006 & $0.048^{*}$ & $0.068^{\star \star}$ & $0.059^{\star *}$ \\
\hline Triglyceride & -0.015 & $0.065^{\star}$ & 0.065 & -0.017 & 0.031 & 0.028 \\
\hline
\end{tabular}

In all regression models, age, body mass index, family history of cardiovascular disease, smoking, and alcohol consumption were adjusted.

T, total; HDL, high-density lipoprotein; LDL, low-density lipoprotein.

alndependent variable is the log-transformed mercury level.

${ }^{\star} p<0.05 ;{ }^{* \star} p<0.01$.

month was $96.50 \mathrm{mg} / \mathrm{dL}$; the median in the female group with consumption 4-8 times a month was $83.00 \mathrm{mg} / \mathrm{dL}$; and the median in the female group with consumption more than 8 times a month was $83.00 \mathrm{mg} / \mathrm{dL}$, showing a trend of significant decrease ( $p$-trend $<0.001)$; the median in the male group with consumption less than 4 times a month was $130.00 \mathrm{mg} / \mathrm{dL}$; the median in the male group with consumption 4-8 times a month was $125.00 \mathrm{mg} / \mathrm{dL}$; and the median in the male group with consumption more than 8 times a month was $119.50 \mathrm{mg} / \mathrm{dL}$, showing a trend of decrease; however, this was not statistically significant $(p$-trend $=0.099)$.
In linear regression analysis with log-transformed blood $\mathrm{Hg}$ level as the independent variable, and each log-transformed dyslipidemia indicator as the dependent variable, after adjustment for age, BMI, CVD family history, smoking, and alcohol consumption, increased $\mathrm{Hg}$ levels showed a significant association with increased TC and LDL-C. This significant association was maintained in the group with fish consumption less than 4 times a month, but disappeared in the group with consumption more than 8 times a month. In addition, increased blood $\mathrm{Hg}$ levels in the group with consumption more than 8 times a month did not show a significant association with either an in- 
crease or decrease in TC, HDL-C, LDL-C, and TG. HDL-C showed a significant association with increased blood $\mathrm{Hg}$ level in female groups, but not in male groups or target participants (Table 3).

\section{DISCUSSION}

This study found that the level of blood Hg was high in dyslipidemic risk groups. As the frequency of fish consumption increased, blood $\mathrm{Hg}$ level also increased, but this trend was not observed for the dyslipidemic indicators. Among the dyslipidemic indicators, TC and LDL-C showed a trend of significant increase as the $\mathrm{Hg}$ level increased, but this trend was not observed in the groups with frequent fish consumption.

The hypothesis that heavy metals are risk factors for CVD and dyslipidemia has been verified by many studies. $\mathrm{Hg}$ and other environmental toxins are preventable exposure factors that account for demographic variations in CVD prevalence rates $[28,29]$. Chronic heavy metal exposure promotes red blood cell and hemoglobin synthesis [17], and lead and cadmium are heavy metals that associated with smoking, which is an important risk factor for CVD mortality [30]. Moreover, the phenomenon of blood $\mathrm{Hg}$ level increasing as the frequency of fish consumption increases has already been reported by many studies. In the national biomonitoring surveys performed in Canada, the Czech Republic, Germany, and the US, it was also reported that fish consumption had a significant association with increased blood Hg level [8-10,31-33]; the same result was reported for a previous KNHANES studies in Korea [5-7,34].

Thus, this study verified previous information. In addition, new information was provided, showing a high association between $\mathrm{Hg}$ exposure and dyslipidemic indicators in groups with less frequent fish consumption but not in groups with frequent fish consumption. Increases in the level of $\mathrm{Hg}$ exposure in groups with less frequent fish consumption may be caused by other factors, such as environmental or occupational exposure, dental amalgam, or smoking. Therefore, $\mathrm{Hg}$ exposure due to factors other than fish consumption may cause increases in cholesterol, but such effects are diminished in groups with a high frequency of fish consumption. This is shown by the findings in this study that blood $\mathrm{Hg}$ level increased in groups with frequent fish consumption, but that no such trend was shown for TC, HDL-C, LDL-C, and TG. Several studies suggested that a high levels of $\mathrm{Hg}$ exposure may diminish the cardioprotective effect of fish consumption $[11,12]$. These results also suggest the fish consumption may diminish the risk of dyslipidemia due to $\mathrm{Hg}$ exposure. Of course, there are few evidence in this study to confirm this hypothesis.
There are several limitations. First, this study has a cross-sectional design and was based on national data. In other words, since various routes and characteristics of $\mathrm{Hg}$ exposure were not investigated over a long period of time, the contribution of fish consumption or other factors on blood $\mathrm{Hg}$ level cannot be determined. Therefore, a trend was observed in the result of this study, but the result of the study cannot explain causation.

Another limitation is that specific information on the types of fish and cooking methods was not provided by the fish consumption frequency survey. Since $\mathrm{Hg}$ and omega- 3 fatty acids content may vary according to the type of fish as well as the form of consumption, more detailed examination is necessary $[35,36]$. The omission of information regarding occupational exposure and dental amalgam is another limitation. These limitations result from the fact that the KNHANES is not designed for evaluation of $\mathrm{Hg}$ exposure alone. As well as fish consumption considered in this study, there are many other dietary characteristics can affect cholesterol profiles such as meat, sodium consumption. However, this study could not consider all these various diet or lifestyle factors.

A difference between males and females was observed for a significant portion of the results in this study. There were differences in the absolute values of each indicator as well as the trend. For example, as the frequency of fish consumption increased in females, HDL-C increased significantly, but LDL-C and TG decreased. This is of positive benefit for CVD and dyslipidemia. However, this trend was not confirmed for males. There may be some factor that accounts for differences between males and females such as smoking, drinking described in Table 1 and occupational exposure also, but the data in this study are not sufficient to identify such a factor.

HDL-C tended to increase as blood $\mathrm{Hg}$ level in female groups increased. HDL-C is also known to have a negative correlation with CVD [37]. Therefore, it is not clear why a positive association between the level of $\mathrm{Hg}$ and HDL-C was only observed in the female groups in this study. However, a trend was seen in females: as the frequency of fish consumption increased, HDL-C increased and LDL-C decreased, indicating that fish consumption had a prominent effect. This also supports a previous report that fish consumption increases HDL-C [38]. Frequent fish consumption should be associated with a low-risk of CVD because of less frequent meat consumption, but it is not certain that meat contributes more to CVD than fish [39].

In conclusion, the results of this study suggest that fish consumption increases the level of $\mathrm{Hg}$ exposure, and that as the level of $\mathrm{Hg}$ exposure increases, the risk of dyslipidemia increases. However, this study also indicates that the risk of dyslipidemia in those consuming frequent fish frequently can be diminished. 


\section{ACKNOWLEDGEMENTS}

This research was supported by the Basic Science Research Program through the National Research Foundation of Korea (NRF) funded by the Ministry of Education (NRF-2013R1A1A2060215).

\section{CONFLICT OF INTEREST}

The author has no conflicts of interest associated with the material presented in this paper.

\section{ORCID}

\section{Yong Min Cho http://orcid.org/0000-0002-8999-8916}

\section{REFERENCES}

1. Curtis D Klaassen CD, Casarett LJ, Doull J. Casarett and Doull's toxicology: the basic science of poisons. 8th ed. New York: McGraw-Hill Education; 2013, p. 947-950.

2. Xu Y, Khoury JC, Sucharew H, Dietrich K, Yolton K. Low-level gestational exposure to mercury and maternal fish consumption: associations with neurobehavior in early infancy. Neurotoxicol Teratol 2016;54:61-67.

3. Yin L, Yu K, Lin S, Song X, Yu X. Associations of blood mercury, inorganic mercury, methyl mercury and bisphenol A with dental surface restorations in the U.S. population, NHANES 2003-2004 and 2010-2012. Ecotoxicol Environ Saf 2016;134:213-225.

4. Ilmiawati C, Yoshida T, Itoh T, Nakagi Y, Saijo Y, Sugioka Y, et al. Biomonitoring of mercury, cadmium, and lead exposure in Japanese children: a cross-sectional study. Environ Health Prev Med 2015;20(1):18-27.

5. Kim NS, Lee BK. National estimates of blood lead, cadmium, and mercury levels in the Korean general adult population. Int Arch Occup Environ Health 2011;84(1):53-63.

6. Lee JW, Lee CK, Moon CS, Choi IJ, Lee KJ, Yi SM. Korea national survey for environmental pollutants in the human body 2008: heavy metals in the blood or urine of the Korean population. Int J Hyg Environ Health 2012;215(4):449-457.

7. Lee H, Kim Y, Sim CS, Ham JO, Kim NS, Lee BK. Associations between blood mercury levels and subclinical changes in liver enzymes among South Korean general adults: analysis of 2008-2012 Korean National Health And Nutrition Examination Survey data. Environ Res 2014;130:14-19.

8. Lye E, Legrand M, Clarke J, Probert A. Blood total mercury concentrations in the Canadian population: Canadian Health Measures Survey cycle 1, 2007-2009. Can J Public Health 2013;104(3):e246e251.

9. Schulz C, Angerer J, Ewers U, Heudorf U, Wilhelm M; Human Biomonitoring Commission of the German Federal Environment Agency. Revised and new reference values for environmental pollutants in urine or blood of children in Germany derived from the German environmental survey on children 2003-2006 (GerES
IV). Int J Hyg Environ Health 2009;212(6):637-647.

10. Mortensen ME, Caudill SP, Caldwell KL, Ward CD, Jones RL. Total and methyl mercury in whole blood measured for the first time in the U.S. population: NHANES 2011-2012. Environ Res 2014; 134:257-264.

11. Houston MC. Role of mercury toxicity in hypertension, cardiovascular disease, and stroke. J Clin Hypertens (Greenwich) 2011; 13(8):621-627.

12. Guallar E, Sanz-Gallardo MI, van't Veer P, Bode P, Aro A, GómezAracena J, et al. Mercury, fish oils, and the risk of myocardial infarction. N Engl J Med 2002;347(22):1747-1754.

13. Kim YN, Kim YA, Yang AR, Lee BH. Relationship between blood mercury level and risk of cardiovascular diseases: results from the Fourth Korea National Health and Nutrition Examination Survey (KNHANES IV) 2008-2009. Prev Nutr Food Sci 2014;19(4): 333-342.

14. Salonen JT, Seppänen K, Lakka TA, Salonen R, Kaplan GA. Mercury accumulation and accelerated progression of carotid atherosclerosis: a population-based prospective 4-year follow-up study in men in eastern Finland. Atherosclerosis 2000;148(2):265-273.

15. Sponder M, Fritzer-Szekeres M, Marculescu R, Mittlböck M, Uhl M, Köhler-Vallant B, et al. Blood and urine levels of heavy metal pollutants in female and male patients with coronary artery disease. Vasc Health Risk Manag 2014;10:311-317.

16. Rotter I, Kosik-Bogacka D, Dołęowska B, Safranow K, Lubkowska A, Laszczyńska M. Relationship between the concentrations of heavy metals and bioelements in aging men with metabolic syndrome. Int J Environ Res Public Health 2015;12(4):3944-3961.

17. Lee YJ, Hwang IC. Relationship between serum ferritin level and blood mercury concentration using data from the Korean National Health And Nutrition Examination Survey (2010-2012). Environ Res 2014;135:271-275.

18. Poursafa P, Ataee E, Motlagh ME, Ardalan G, Tajadini MH, Yazdi $\mathrm{M}$, et al. Association of serum lead and mercury level with cardiometabolic risk factors and liver enzymes in a nationally representative sample of adolescents: the CASPIAN-III study. Environ Sci Pollut Res Int 2014;21(23):13496-13502.

19. Bélanger MC, Mirault ME, Dewailly E, Plante M, Berthiaume L, Noël M, et al. Seasonal mercury exposure and oxidant-antioxidant status of James Bay sport fishermen. Metabolism 2008;57(5):630636.

20. Kris-Etherton PM, Harris WS, Appel LJ; Nutrition Committee. Fish consumption, fish oil, omega- 3 fatty acids, and cardiovascular disease. Circulation 2002;106(21): 2747-2757.

21. Lee BK, Kim Y. Iron deficiency is associated with increased levels of blood cadmium in the Korean general population: analysis of 2008-2009 Korean National Health and Nutrition Examination Survey data. Environ Res 2012;112:155-163.

22. Kim NS, Lee BK. Blood total mercury and fish consumption in the Korean general population in KNHANES III, 2005. Sci Total Environ 2010;408(20):4841-4847.

23. Park SK, Lee S, Basu N, Franzblau A. Associations of blood and urinary mercury with hypertension in U.S. adults: the NHANES 2003-2006. Environ Res 2013;123:25-32.

24. McGuire S. U.S. Department of Agriculture and U.S. Department of Health and Human Services, Dietary Guidelines for Americans, 
2010. 7th Edition, Washington, DC: U.S. Government Printing Office, January 2011. Adv Nutr 2011;2(3):293-294.

25. Expert Panel on Detection, Evaluation, and Treatment of High Blood Cholesterol in Adults. Executive summary of the third report of the National Cholesterol Education Program (NCEP) expert panel on detection, evaluation, and treatment of high blood cholesterol in adults (Adult Treatment Panel III). JAMA 2001; 285(19):2486-2497.

26. Lee JB, Yi HY, Bae KH. The association between periodontitis and dyslipidemia based on the Fourth Korea National Health and Nutrition Examination Survey. J Clin Periodontol 2013;40(5):437442.

27. Chung CE. Complex sample design effect and inference for Korea National Health and Nutrition Examination Survey data. Korean J Nutr 2012;45(6):600-612 (Korean).

28. Bhatnagar A. Environmental cardiology: studying mechanistic links between pollution and heart disease. Circ Res 2006;99(7): 692-705.

29. Weinhold B. Environmental cardiology: getting to the heart of the matter. Environ Health Perspect 2004;112(15):A880-A887.

30. Aoki Y, Brody DJ, Flegal KM, Fakhouri TH, Axelrad DA, Parker JD. Blood lead and other metal biomarkers as risk factors for cardiovascular disease mortality. Medicine (Baltimore) 2016;95(1): e2223.

31. Batáriová A, Spevácková V, Benes B, Cejchanová M, Smíd J, Cerná $\mathrm{M}$. Blood and urine levels of $\mathrm{Pb}, \mathrm{Cd}$ and $\mathrm{Hg}$ in the general population of the Czech Republic and proposed reference values. Int J Hyg Environ Health 2006;209(4):359-366.
32. Cerná M, Krsková A, Cejchanová M, Spěváčková V. Human biomonitoring in the Czech Republic: an overview. Int J Hyg Environ Health 2012;215(2):109-119.

33. Becker K, Schroeter-Kermani C, Seiwert M, Rüther M, Conrad A, Schulz C, et al. German health-related environmental monitoring: assessing time trends of the general population's exposure to heavy metals. Int J Hyg Environ Health 2013;216(3):250-254.

34. Seo JW, Kim BG, Kim YM, Kim RB, Chung JY, Lee KM, et al. Trend of blood lead, mercury, and cadmium levels in Korean population: data analysis of the Korea National Health and Nutrition Examination Survey. Environ Monit Assess 2015;187(3):146.

35. Mahaffey KR. Mercury exposure: medical and public health issues. Trans Am Clin Climatol Assoc 2005;116:127-153.

36. Tsuchiya A, Hinners TA, Krogstad F, White JW, Burbacher TM, Faustman EM, et al. Longitudinal mercury monitoring within the Japanese and Korean communities (United States): implications for exposure determination and public health protection. Environ Health Perspect 2009;117(11):1760-1766.

37. Connelly MA, Shalaurova I, Otvos JD. High-density lipoprotein and inflammation in cardiovascular disease. Transl Res 2016;173: 7-18.

38. Zaribaf F, Falahi E, Barak F, Heidari M, Keshteli AH, Yazdannik A, et al. Fish consumption is inversely associated with the metabolic syndrome. Eur J Clin Nutr 2014;68(4):474-480.

39. Maki KC, Van Elswyk ME, Alexander DD, Rains TM, Sohn EL, McNeill S. A meta-analysis of randomized controlled trials that compare the lipid effects of beef versus poultry and/or fish consumption. J Clin Lipidol 2012;6(4):352-361. 